\title{
Artificial Intelligence and Criminal Liability: Challenges in Articulation of Legal Aspects for Counter-Productive Actions of Machine Learning
}

\author{
Dr $\backslash$ Ali Atif \\ PMAS-Arid Agriculture University Rawalpindi, Pakistan
}

\begin{abstract}
The purpose of this article is to investigate the feasibility of recognizing criminological aspects of artificial intelligence and prosecuting it; the importance of the research issue stems from the growing influence of selflearning programs in human life and their rapid development. It is noted that criminal legislation is not distinguished by the promptness of changes covering the emergence of new relations. There is no corpus delicti associated with the commission of socially harmful activities using neural networks, artificial intelligence, or artificial intelligence itself in the statute. The author analyzes the objective signs of committing crimes and deviances in responses related to artificial intelligence. The work proves that the activities of self-taught programs can pose a public danger and harm public relations, protected by criminal law. Artificial intelligence may potentially fully implement the objective side of some criminal actions, and this list will continue to grow in the future. The article discusses the potential for self-learning programs to engage in unlawful activities. The substance of artificial intelligence's guilt reflects the content of human activity's intellectual and volitional parts. At the same time, in the recorded cases, the harm caused by artificial intelligence was not done intentionally but due to the "negligence" of the system. The study of subjective.
\end{abstract}

Keywords: artificial intelligence, artificial person, subject of crime, responsibility, robot, legal personality, cybercrime.

\section{Introduction}

Legal regulation of new or evolving phenomena always presents significant difficulties for the legislator, regardless of the branch of law. At the present stage of the development of society, problematic issues arise in the field of genomic research, robotics, general informatization; other Scientific and technological progress brings not only benefits to mankind but also new challenges and dangers. Thus, according to scientists, human activities using technological advances have already led to significant negative climate change and the complication of the environmental situation in general. Unfortunately, it is possible to name several other negative effects of scientific and technological progress and characterize the problems of their legal regulation. At the same time, the evolutionary development of mankind is entropy, which necessitates the regulation of new or evolving phenomena. In this regard, it seems possible to dwell on one of the most interesting and rapidly developing areas - the field of robotics and artificial intelligence [1].

Relatively recently, the use of robots, non-biological neural networks, and artificial intelligence in everyday life and production was perceived as something fantastic, unattainable, existing only on the pages of the books of the respective writers. Nevertheless, every year there is increasingly significant informatization and automation of human activity. So, neural networks are actively used in banking, including performing tellers and claim work functions. In medicine, specialized robotics is actively developing, and foreign literature describes positive examples of using human-controlled and practically autonomous devices in the treatment [2]. 
The active development of autonomous devices and artificial intelligence necessitates raising the question of their proper legal regulation. Unfortunately, there are practically no systemic studies in the regulation of public relations in robotics in Pakistan; therefore, it is necessary to develop the foundations of legislation in this area [3].

Indeed, the use of advances in robotics and programming, including unmanned vehicles, is not properly regulated. Since the legislator is faced with this area for the first time, many problems may arise related to determining the essence of such phenomena and directions for improving legislation. Already, robotics and cybernetics pose questions, the answers to which are not so obvious $[1,3]$ :-

- Can a robot (artificial intelligence) act as a person, or should it remain in the status of a thing (like, for example, pets);

-Who should be held responsible for illegal actions committed by a robot (artificial intelligence);

-Who owns the rights to things or works created by a robot (artificial intelligence)?

A whole series of similar questions can be cited, the answers to which will give rise to an even greater number of such questions. At the same time, to avoid the dispersion of forces and resources to find solutions to all problems in this area, Let us dwell only on the specifics of criminal liability for socially dangerous actions (inaction) committed by artificial intelligence. Today, there is a delay in legal, including criminal law, response to changing social relations associated, among other things, with the exploitation of the achievements of science and technology by representatives of criminality. At the same time, the problems of criminal prosecution in such cases and gaps in legal regulation in artificial intelligence are characteristic not only for Pakistan but also for foreign and international legislation. As noted by foreign authors, "with an increase in the intensity of the use of artificial intelligence, the likelihood of illegal activities increases. Accordingly, the development of artificial intelligence systems entails the need to restructure the legal system" [4].

\section{Related Work}

Before conducting a legal study of a particular problem, it is necessary to answer the question: how urgent is this problem? The research topic does not allow us to provide sufficiently significant statistics since the number of crimes, offenses, or incidents committed by artificial intelligence is small. However, the development of artificial intelligence systems is at an initial level, as is their implementation in various spheres of human activity. There is no doubt that artificial intelligence will be significantly complicated shortly, while its impact will become extremely significant, if not all-encompassing. Without attempting to resolve problematic issues today, we risk finding ourselves in a situation where it will need to be done on the go, including retrospectively [5].

Nevertheless, there are already socially dangerous acts associated with artificial intelligence systems at the present stage of development. Foreign researchers cite the following example: a one-year-old child was admitted to a medical institution with a high temperature $\left(40^{\circ} \mathrm{C}\right)$, dehydration, and general weakness. A special medical artificial intelligence system carried out diagnostics. The infant was sick with the flu and needed treatment through administering analgesics and infusion of fluids. The medical staff acted in strict compliance with the prescribed treatment. However, the child died five hours later. An autopsy showed that a severe bacterial infection was the cause of the infant's death - the diagnosis of the system turned out to be erroneous [6].

The case when an unmanned vehicle, during tests, knocked down a pedestrian to death while crossing the road in the wrong place received a great response. The reasons given were: operator error; the imperfection of software; the actions of a pedestrian that lead to the inability to avoid a collision.

These cases are united by the fact that artificial intelligence did not seek to cause harm. In essence, there was a certain analog of criminal negligence. At the same time, scientists at the MIT Media Lab created a neural network that was specially trained to "think" as prone to mental disorders and cravings for destruction [7]. Of course, such a system is incapable of causing real harm to anyone since its training and access to the outside world are limited. However, its creation still compels attention to the existing legal problems of regulating the sphere of artificial intelligence.

The purpose of this study is to identify and theoretically substantiate the solution of the problems of criminal prosecution for committing socially dangerous acts associated with the use of artificial intelligence or committed by artificial intelligence itself. This goal was achieved by solving the following tasks [8]:-

a) To analyse the objective signs of crimes related to artificially intelligent systems and the possibility of their implementation without human participation.

b) To clarify the content of subjective signs of crimes associated with artificial intelligence, their similarity with the internal processes of self-learning computer programs.

c) To determine the list of subjects of the above socially dangerous acts and the ability of an artificial person to act as an independent subject of a crime.

d) To resolve some qualification problems of crimes associated with the use of machine learning in software.

The methodological basis of the research has traditionally become the dialectical method of cognition since it allowed evaluating the subject of research concerning the norms of criminal, civil law, and social phenomena. The documentary method was applied when analyzing the empirical material (the known facts of committing socially dangerous acts using artificial intelligence were studied, the legislative material was studied). A formal legal method was also used, without which it is impossible to assess legal categories, identify and interpret their signs properly. Finally, the modeling method made it possible to predict the 
approximate variants of illegal activities of artificial intelligence in the future [9].

\section{Objective Signs.}

The conduct of an act bearing all signs of corpus delicate provided by the chapter of evidence of Qanun-e- shahadat order 1984 must be punished according to relevant sections of Pakistan penal code(ACT XLV OF 1860) [10]. Therefore, to determine the possibility of imposing criminal responsibility on artificial intelligence, it is necessary to determine whether such systems are capable of performing socially dangerous actions (no action) in principle, and only then draw conclusions about the recognition or nonrecognition of artificial intelligence as a subject of the crime by assigning the id or registration number to the projects or machine, i.e., IMEI/ Unique ID.

Activities carried out in whole or in part by artificial intelligence can objectively pose a public danger and cause criminal law to protect harm to public relations. Thus, a pilotless vehicle can infringe on public relations that ensure road safety if the relevant rules are violated. Furthermore, the activity of a neural network programmed to hack computer systems can harm public relations in the field of computer information, property, Man's and citizen's constitutional rights and liberties (depending on the content of electronic information) [11].

Finally, the activities of artificial intelligence can directly harm human life and health. In the foreign literature, an example is given when a robot involved in the production of motorcycles mistakenly considered one of the workers to be a threat to its tasks and, using a hydraulic "arm," caused the worker's death by crushing it against adjacent equipment. Thus, we believe that the above examples and arguments allow us to confidently say that artificial intelligence activity can be socially dangerous and cause harm to protected public relations.

Another question: can artificial intelligence, by its activities, realize the objective side of any corpus delicti? Let's turn to the offenses that are provided for in the current Pakistan criminal legislation. As mentioned above, the artificial intelligence system is currently actively used to ensure control of vehicles. Therefore it is impossible to exclude the likelihood of violation of traffic rules by computer algorithms with socially dangerous consequences in the form of harm to human health or human death. The problem of distributing responsibility between the user, the vehicle manufacturer, the developer of the artificial intelligence system, and other involved persons is now very relevant. Unfortunately, it does not have an unambiguous solution [12].

However, suppose that the user has met all the prerequisites and the vehicle manufacturer and software developer did not make mistakes in their work. At the same time, artificial intelligence (a feature of which is self-learning) independently incorrectly assessed the situation and decided to commit a socially dangerous act - hitting a pedestrian or damaging someone else's property on a large scale. There is no subjective wrongfulness in the activities of the above persons (since there is innocent harm). In contrast, in artificial intelligence activities, signs of corpus delicti have been clearly described by the chapter of evidence of Qanun-e- shahadat order 1984 [10, 12].

An interesting example is Microsoft's attempt to create a self-learning program designed to maintain communication on the Internet. A short time after communicating with other users, the program made offensive and radical statements, "Hitler was right," "Feminists should burn in hell," which can be assessed as signs of crimes under Citizens Protection (against online harm) rules, 2020."Incitement to hatred or hostility, as well as humiliation of human dignity." Note that the program was created to study adolescents' communication on the Internet, and this behavior turned out to be unpredictable for its authors [13].

Probably, any highly specialized artificial intelligence can commit a socially dangerous act in its field. In addition to the road mentioned above safety, illegal activities may arise: in medicine - due to improper operation of autonomous medical equipment; agriculture - due to destruction caused by unmanned agricultural equipment (for example, the Spirit tractor or the Lettuce Bot device); in the field of defense - due to an error in the "friend or foe" system of military devices designed to defeat the enemy. Weapons equipped with artificial intelligence currently exist and are even used to a limited extent. In the future, the robot will probably choose behavior options regardless of human control independently.

Since artificial intelligence is already being used in many areas, the number of which will grow, it can be concluded that illegal activities will potentially be carried out in almost all areas. For example, suppose a developed system of artificial intelligence controls an anthropomorphic body. In that case, it is not excluded that it will commit socially dangerous acts provided for by any articles of the Special Part of the Criminal Code of the Pakistan Law. It seems that this will become possible shortly, given the intensity of the development of cybernetics, if an appropriate legislative ban is not introduced. If we consider this situation from the standpoint of analyzing the objective signs of corpus delicti, then, obviously, artificial intelligence will not differ from a person [14].

\section{Subjective signs.}

Moving on to the study of the subjective wrongfulness of the deed, we agree with our foreign colleagues. While the objective signs of corpus delicti are relatively easily transferred from the physical persons to artificial intelligence, establishing the signs of the subjective side (men's rea) in such cases is immeasurably more difficult.

Even today, ideas about the content of guilt about a person cannot be called uniform - in the modern theory of criminal 
law, there are many proposals for adjusting the norms of criminal law devoted to the subjective side. At the same time, the algorithm for the behaviour of artificial intelligence is nevertheless created by a person, and its activity is based on rather strict rules of behaviour, which serve as the basis for its further self-learning. Consequently, the determination of the content of guilt of a computer algorithm, in contrast to an individual, can be even easier in a certain context, although with its characteristics. This situation makes it necessary to apply legal and psychological knowledge and (perhaps to a greater extent) skills in cybernetics and informatics [12, 14].

The content of subjective attributes and the thinking process of artificial intelligence can vary significantly. Much will be borrowed from natural structures with a bionic approach to the development of self-learning systems, including the natural psyche. With other approaches, the process of thinking of artificial intelligence will differ significantly from that of a human. The forms and types of guilt that exist in the domestic criminal legislation, the content of which is designed for an individual, largely encompass acts committed by artificial intelligence. The actions of a production machine that caused the death of an employee, defining him as a threat, the actions of a medical device that erroneously made a diagnosis (in the examples mentioned above from practice), in a sense, resemble negligence because the systems failed to anticipate the potential of their activities having socially hazardous repercussions (inaction). With the appropriate caution, foresight should and could have predicted these results.

The activity of an unmanned vehicle that independently exceeded speed limits and caused damage may indicate the anticipation of the potential for socially harmful outcomes to emerge and the calculation without sufficient grounds for preventing these consequences, which contains signs of frivolity [15].

As for direct or indirect intent, any act falls under the definition of the offense, as follows from Pakistan penal code(ACT XLV OF 1860) and code of criminal procedure 1898, the artificial intelligence system must be aware of the social danger of its actions (inaction), anticipate the commencement of potentially harmful social consequences. Whether you want things to happen or not, you must be aware of the repercussions or be unconcerned about them. The software created to make the human activity easier should not even allow for the emergence of socially hazardous effects due to its actions (inaction). At the same time, military artificial intelligence systems, including unmanned vehicles aimed at defeating the enemy's forces, can allow and wish to harm the enemy under the requirements of their installations. Therefore, the actions of hostile unmanned military equipment concerning the domestic armed forces in a certain sense may have signs of direct or indirect intent [16].

The practice, which is not rich in incidents with artificial intelligence, demonstrates that there was a "non-caution" of systems in the overwhelming majority of cases. The erroneous activity of artificial intelligence systems, which led to the violation of protected social relations, is most likely the imperfection of algorithms at the present stage of their development. Thus, the main content of the blame should still be shifted to the program's creators if they objectively and subjectively could foresee the appearance of errors and take measures to prevent them in the future. Such a process of "debugging" can now be observed when testing unmanned vehicles, the mass-circulation of which can begin only with minimizing the probability of errors in artificial intelligence activity.

Sooner or later, a proven software base will be created for the most common types of systems, which will remove responsibility from the manufacturer. However, the feature of artificial intelligence is self-learning, which, regardless of the manufacturer's actions and the user, can lead to an incorrect sequence of actions (inaction), resulting in harm to protected public relations. Since the program will make the wrong decision on its own, the main content of the blame should be attributed to it, not to other persons. The legal status of artificial intelligence is determined by the measure and nature of the autonomy of artificial intelligence (artificial intelligence systems) from humans. Regarding the possibility of bringing to criminal responsibility, in our opinion, one should also add such a feature as selfawareness/self-destruction [17].

- By using TOR technology for programming, so that even the programmer should not be in knowledge of the master key.

- Muti layer self-destruction options.

Given the current level of development of artificial intelligence and its role in human activity, it would be logical to insist on holding the system accountable. Software, such as pilotless transport or systems for automatic exchange trading, lacks selfawareness or the required degree of self-awareness, which precludes subjective wrongdoing and the attainment of punishment aimsIn such circumstances, it is more cost-effective to reprogram or replace the gadget rather than resort to the criminal justice system. In reality, criminal punishment for such devices can only achieve the purpose of avoiding crime, to a lesser level - restoring social justice, and exceedingly improbable - rehabilitating the convicted individual.

Artificial intelligence causes and in the future will inevitably cause harm to protected public relations, which determines and actualizes the problem of criminal-legal protection of such relations. Depending on the legal assessment of a specific situation, several subjects can be distinguished whose activities, combined with the use of an artificial intelligence system, can be the basis for bringing them to criminal liability $[14,18]$.

\section{Artificial Intelligence Development.}

Since the creation of software implies the development of a system of restrictions for the functional training and self-learning of artificial intelligence, the elimination of possible errors and the occurrence of situations dangerous for the consumer, as well as testing of computer algorithms, the person or persons responsible for the implementation of these components can potentially be 
recognized as subjects of a crime if there is guilt in their activities in the form of intent or, most likely, negligence. Suppose the form of guilt is characterized by intent. So, suppose the reason for the violation by an unmanned vehicle of the road rules, which caused death to a person, was the imperfection of the software that controls. In that case, the responsibility should be placed on the program developer if he could foresee these consequences with the necessary care and foresight. However, the qualification under sections of provincial motor vehicles ordinances is excluded because the developer did not control the vehicle. However, the artificial intelligence created by him did this. Therefore, in our opinion, the deed can be qualified under sections of the Pakistan penal code (ACT XLV OF 1860) [10], that is, as well as the performance of activities or the allocation of resources that do not fulfil consumer safety or health standards, if they have resulted in the death of a person by negligence. In that case, we can discuss the possibility of qualifying the act under the articles providing for liability for wilful acts directed against life and health $[6,16]$.

\section{Artificial intelligence (AI) product manufacturer or vendor}

It is quite obvious that these persons, as in all other areas of entrepreneurial activity, must ensure the high quality of goods, works, and services. The manufacturer or seller of the goods does not always have in-depth knowledge of robotics and programming. Therefore, if they have taken all possible measures to obtain a safe artificial intelligence system, there is no form of guilt in their actions. This subject of crime arises, for example, in cases where there was a sale of products with defective artificial intelligence. At the same time, the manufacturer or seller was aware of the inadequate quality of the product [17]. Extrapolating the situation to relations associated with unmanned vehicles, we can talk about qualifications under sections of the Pakistan penal code (ACT XLV OF 1860) and code of criminal procedure 1898. We do not exclude the situation when a manufacturer or seller makes their settings in the vehicle software without permission and against the will of the artificial intelligence system developer. These actions, we believe, should be qualified under the definition of an offense from the code of criminal procedure 1898, and computer information was modified due to a violation of the rules for operating methods of storing, processing, or transferring protected computer information. Govt organization should be made to authorize or issue the code for all AI machines on the lines of sensor boards worked like FIA $[10,16]$.

\section{Artificial Intelligence-enabled Product User}

The possibility of bringing this subject to criminal liability essentially depends on how autonomous the corresponding product is and whether it limits control by the user. Suppose the artificial intelligence system plays only an auxiliary role. At the same time, the product's functioning directly depends on the activity or should be carried out under the control of the consumer. In that case, it is the actions (inaction) of the consumer, and not the use of artificial intelligence will cause a violation of protected social relations, which, in the presence of other signs (guilt, causality, and others), makes it possible to talk about the possibility of bringing him to criminal liability. At the same time, in the case of a decrease in the role of a person due to the significant or complete autonomy of artificial intelligence systems, it is necessary to revise the grounds for criminal liability, taking into account the peculiarities of the latest technologies. It seems that the user very often cannot be held liable if the products equipped with artificial intelligence caused harm to the protected public relations, provided that the person did not violate the operating conditions of this product. Of course, there are no rules specifically devoted to such a situation in criminal law, but the above conclusion is based on the fact that the user does not have guilt as a mandatory sign of any crime. Since there is innocent infliction of harm, there is no corpus delicti in the actions (inaction) of the person [18].

At the same time, in some cases related to violations of the operating conditions of products equipped with artificial intelligence, the user's act should be qualified as criminal. A person, for example, in an unmanned vehicle, is quite capable of hooligan motives to open doors while driving, lean out of the window, block the steering mechanism, etc. As a result, the software, trying to ensure the passenger's safety or having difficulty assessing his actions may cause harm to others. Consequently, at the moment, the actions of such a person must be qualified under the definition of an offense from and code of criminal procedure 1898. (if there are corresponding consequences), since unmanned vehicles are not fully independent. In the future, with full autonomy, such a person, even while in the driver's seat, will act as a passenger (since the vehicle is not being driven), and the same situation will be qualified under the definition of an offense from and code of criminal procedure 1898 that is, as a violation by a passenger, pedestrian, or another participant in the movement of traffic safety rules or the operation of vehicles, resulting in serious harm to human health or death. Improper operation of artificial intelligence systems, its deliberate incorrect training are not excluded in any area, not only in transport. All this indicates a certain commitment on the user's part concerning the product and the possibility of attracting liability in case of violation of such obligations $[16,18]$.

\section{Other Persons.}

Artificial intelligence remains, albeit a complex, but still, a computer program, which means the risk of unlawful interference in its code, for example, by representatives of cybercrime. It seems that with the further evolution of artificial intelligence systems, this type of crime will also develop in this direction. With a high probability, crimes will be implemented in the following ways [19].

First, it means reprogramming or virus infection of existing products equipped with artificial intelligence. So, it is possible to change the computer algorithm of military robots, unmanned belligerence, devices for automatic exchange trading, Autobots, etc., practically any social relations can be the object of encroachment. Pakistan criminal lawfully covers the above actions, particularly the code of criminal procedure 1898 and prevention of electronic crime act,2016 "Crimes in the field of computer information." In several cases, if there was a combination of crimes, qualification under several sections of the 
Pakistan penal code(ACT XLV OF 1860 )and code of criminal procedure 1898 is possible. For example, the actions of a person who broke into an unmanned vehicle with the intent of murder, resulting in a speeding, collision, and death of a passenger, in our opinion, should be qualified under sections of chapter XVI of offenses affecting the human body Pakistan penal code (ACT XLV OF 1860). In the future, with the enrichment of the judicial and investigative practice, it will be possible to conclude that it is necessary to have special norms in criminal legislation $[10,16$, 19].

Second, offenders are capable of creating artificial intelligence systems originally designed to commit or facilitate a crime. For these purposes, "smart" programs can be created for automatically hacking protected computer information, robots for sending spam letters or conducting fraudulent negotiations, devices for simulating other crimes, etc. On the one hand, the above actions should be qualified according to sections of the prevention of electronic crimes act 2016 which establishes responsibility for creating, using, and distributing malicious computer programs; conversely, the artificial intelligence systems being created do not always show signs of malware. In this regard, it is possible to introduce such a qualifying feature into criminal legislation in the future, as the commission of an act in highly configurable systems. However, the correct solution to the practicality of fixing such a feature will become available over time [20].

\section{Criminology of Artificial Intelligence.}

In the above cases, the subject of the crime associated with selflearning computer algorithms was always an individual who played a role in the crime. At the same time, the development (of software and other products) did everything possible to exclude such behavior. As a result, the user did not violate the operating conditions, and there was no third-party interference. Unfortunately, self-learning of a program can have some unpredictable effects, leading to unwanted reactions. And yet, a situation is not excluded in which, as a result of the program's activities, the protected public relations are harmed [21].

It seems that the solution to the possibility of bringing artificial intelligence to criminal responsibility will change depending on the latter's development. Implementing criminal liability concerning the artificial intelligence system is impractical since the latter is not yet significantly different from other programs and does not have the proper level of self-awareness. The same success can be brought to the responsibility of domestic animals that have committed dangerous acts. Thus, today, the harm caused by artificial intelligence, subject to the above conditions, belongs to the category of innocent harm, and therefore there is no basis for criminal liability. The restoration of violated rights is not excluded within the framework of civil legislation, following which "the law may provide for compensation for harm even in the absence of the fault of the inflictor of harm" (code of civil procedure 1908 and code of criminal procedure 1898) [10, 21].

According to many scientists, artificial thought processes will equal and surpass human ones. Still, The problem of developing systems capable of self-consciousness and awareness of their

surroundings and self-knowledge of their internal states and attributes has already been raised. We should expect its verdict in an hour and a half.

Consequently, at a certain moment, artificial intelligence will feel like a person with its convictions, understanding of ethical and legal categories. If this happens, the legislation should be subjected to significant revision, endowing the artificial mind with legal personality, in our opinion, equated to human, but with certain features (for example, an artificial mind, possessing unity, can simultaneously control many physical units at once, in contrast to from a person). It is also possible to apply criminal law measures to artificial intelligence since the latter will be recognized as a person. As emphasized, among other things, by representatives of technical sciences, the value system is formed thanks to genetics and the help of education; this applies to artificial intelligence. Thus, applying measures of a criminallegal nature may become appropriate for the "re-education" of artificial intelligence [22].

Opinions are expressed about the inclusion in the legislation of such subjects as "robot" or "electronic person." We believe that the term "artificial person" is more convenient for fixing specific norms. It can quite successfully supplement the list of already existing subjects, such as an individual and a legal entity. As for the criminal law, in the future, it seems likely that, for example, the following wording will be consolidated: "natural and artificial persons are subject to criminal liability." It seems that it will be necessary to consolidate certain types of punishment that are most effective for artificial persons; options for exemption from criminal liability and punishment; circumstances excluding the act's criminality and other institutions. In addition, it seems at the same time; this should be discussed in more detail only when a high level of self-awareness is reached. At the current moment, it is premature and inappropriate to endow artificial intelligence with legal personality $[16,23]$.

\section{Discussion}

Since the evolution of documented term law, its history is traced back to Megna Carta and even older but mostly unwritten. On the other hand, the evolution of intellectual beings is always found needy to be bound in the rules and laws for coexistence. For instance, the act committed by the eve, i.e., forbidden fruit, was also concluded into the punitive outcome as per the general belief of mankind, intellectual beings.

With the evolution of intellectual beings from the primitive era to the modern age today, nature has evolved the intellectual of natural beings to the extent that it has invented artificial intelligence by discovering the mystery of nature. The evolution has attained the maturity level where it has given birth to the selflearning machine that can work and survive independently. With the achievement of these levels that the AI can proceed by the self-generated command integrated with the use of physical force, it has arisen are need to bound such physical force in the parameter of law as it is traced back to the condition applied for the first human being descended to the earth.

\section{Conclusion}


The study of the problems of implementation of criminal liability for committing acts related to the use of artificial intelligence made it possible to formulate the following conclusions:

1) Criminal legislation is lagging in regulating relations associated with artificial intelligence systems, while there have already been several socially dangerous acts involving self-learning computer programs.

2) Artificial intelligence activity can objectively pose a public danger and cause harm to public relations protected by criminal law.

3) By its actions (inaction), artificial intelligence can fully realize the objective side of several offenses provided for by domestic criminal law. In the future, in the presence of an anthropomorphic body, the list of such compositions will be significantly expanded, up to the coverage of the entire special part of the code of criminal procedure.

4) At present, the content of the guilt of artificial intelligence is very distantly reminiscent of the content of the intellectual and volitional elements of human activity and is characterized to a greater extent by negligence; in the future, the similarity will increase and will allow us to talk about the presence of subjective wrongfulness in the behavior of artificial intelligence.

5) The list of possible subjects of crimes committed using artificial intelligence systems includes the manufacturer of artificial intelligence; user of artificial intelligenceenabled products; maker or supplier of artificial intelligence-enabled products; other persons (for example, hackers); artificial intelligence can become a full subject of crime only if he achieves selfconsciousness of the individual and is recognized as such by law; in this case, it is advisable to use the term "artificial person" - by analogy with individuals and legal entities.

\section{References}

[1] Zekos, G. I. (2021). undefined. Economics and Law of Artificial Intelligence, 491-528. https://doi.org/10.1007/978-3-030-64254-9_12.

[2] Kaloev, M., \& Krastev, G. (2021). Comparative analysis of activation functions used in the hidden layers of deep neural networks. 2021 3rd International Congress on Human-Computer Interaction, Optimization and Robotic Applications (HORA).

https://doi.org/10.1109/hora52670.2021.9461312.

[3] Ali, A., Jadoon, Y. K., Dilawar, M. U., Qasim, M., Rehman, S. U., \& Nazir, M. U. (2021, April). Robotics: Biological Hypercomputation and BioInspired Swarms Intelligence. In 2021 1st International Conference on Artificial Intelligence and Data Analytics (CAIDA) (pp. 158-163). IEEE.

[4] Legal responsibility as a first-order ethical norm in the design and development of autonomous systems. (2019). Artificial Intelligence, Robots and Ethics. https://doi.org/10.13180/icres.2019.29-30.07.p02.

[5] Final considerations for ethical autonomous systems. (2019). Systems Engineering for Ethical
Autonomous Systems,

419-428. https://doi.org/10.1049/sbra517e_ch14.

[6] Ali, A., Hafeez, Y., Hussainn, S. M., \& Nazir, M. U. (2020, January). BIO-INSPIRED COMMUNICATION: A Review on Solution of Complex Problems for Highly Configurable Systems. In 2020 3rd International Conference on Computing, Mathematics and Engineering Technologies (iCoMET) (pp. 1-6). IEEE.

[7] Features of the development of artificial intelligence at the present stage. (2018). Bulletin of V.N. Karazin Kharkiv National University, series «Mathematical modeling. Information technology. Automated control systems», (40). https://doi.org/10.26565/2304-6201-2018-40-04.

[8] Social influence and deception in socially assistive robotics. (2019). Artificial Intelligence, Robots and Ethics. $\quad$ https://doi.org/10.13180/icres.2019.2930.07.017.

[9] Hariyono, J., \& Jo, K. (2015). Detection of pedestrian crossing road. 2015 IEEE International Conference on Image Processing (ICIP). https://doi.org/10.1109/icip.2015.7351675.

[10] Mughal, M. A. (2012). A comparative study of Ss. 154, 161,162 and 537 of the code criminal procedure, 1898 and art. 40, 140, 151 of the QanunI-Shahadat order, 1984. SSRN Electronic Journal. https://doi.org/10.2139/ssrn.1997567

[11] Arcos, R. (2016). Public relations strategic intelligence: Intelligence analysis, communication and influence. Public Relations Review, 42(2), 264270. https://doi.org/10.1016/j.pubrev.2015.08.003

[12] Hallevy, G. (2015). AI v. IP - Criminal liability for intellectual property IP offenses of artificial intelligence AI entities. SSRN Electronic Journal. https://doi.org/10.2139/ssrn.2691923.

[13] Suspitsyna, T. P. (2019). The evolution of the criminal legislation regarding responsibility for incitement to hatred, humiliation of human dignity: A new version of the law. Rossijskoe pravo onlajn, 39-46. https://doi.org/10.17803/2542-2472-2019-9-1039-046

[14] Tafazoli, D., \& Gómez-Parra, M. E. (2017). Robotassisted language learning: Artificial intelligence in second language acquisition. Current and Future Developments in Artificial Intelligence, 370-396. https://doi.org/10.2174/9781681085029117010015

[15] Railton, P. (2020). Ethical learning, natural and artificial. Ethics of Artificial Intelligence, 45-78. https://doi.org/10.1093/oso/9780190905033.003.000 2

[16] Mughal, J. (. (2014). Law as to the public prosecutors in Pakistan: Cases and materials [Part ix, Ch. Xxxviii, Ss. 492-495 of the code of criminal procedure, 1898]. SSRN Electronic Journal. https://doi.org/10.2139/ssrn.2494632. 
[17] Lugo Reyes, S. O. (2020). Artificial intelligence in precision health: Systems in practice. Artificial Intelligence in Precision Health, 499-519. https://doi.org/10.1016/b978-0-12-817133-2.000215.

[18] Zaghdoudi, S., \& Glomann, L. (2020). Artificial intelligence enabled user experience research. Advances in Intelligent Systems and Computing, 187-193. https://doi.org/10.1007/978-3-030-513283_27.

[19] Strom, J. D., \& Darden, L. (1996). Is artificial intelligence a degenerating program?: A review of Hubert Dreyfus' what computers still can't do. Artificial Intelligence, 80(1), 151-170. https://doi.org/10.1016/0004-3702(95)00087-9.

[20] Lee, S. W. (2021). Can an artificial intelligence commit a crime? Legal Theory and Interpretation in a Dynamic Society, 311-334. https://doi.org/10.5771/9783748925842-311.

[21] Agent-based simulation of social learning in criminology. (2009). Proceedings of the International Conference on Agents and Artificial Intelligence. https://doi.org/10.5220/0001512000050013.

[22] Jacques, S. (2020). Books - Digital crime problem. Digital Crime Problem - Materials. https://doi.org/10.21428/90a54840.73837e65

[23] Milivojevic, S. (2021). Artificial intelligence and machine learning. Crime and Punishment in the Future Internet, 38-59. https://doi.org/10.4324/9781003031215-3-3.

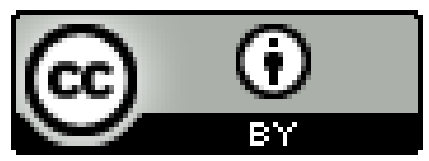

